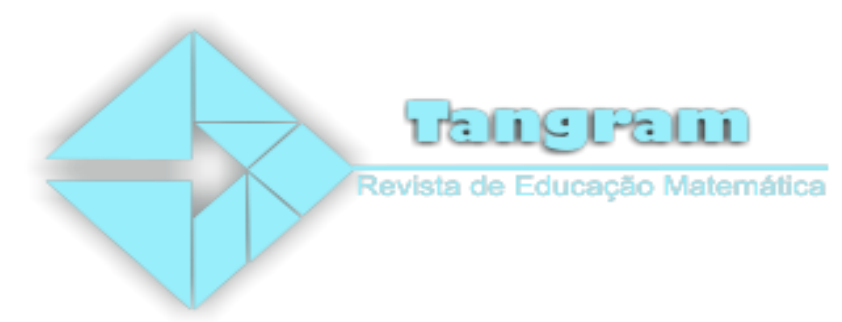

\title{
Educação Financeira em Situações de Ensino e de Aprendizagem: Momentos de Reflexão
}

\section{Financial Education in Teaching and Learning Situations: Moments of Reflection}

\author{
Luís Felipe Gonçalves Carvalho ${ }^{1}$ \\ Bruno Pereira de Matos Silva ${ }^{2}$ \\ John Anderson Ferreira Pereira ${ }^{3}$ \\ Chang Kuo Rodrigues ${ }^{4}$
}

\begin{abstract}
Resumo:Este trabalho discorre sobre a relevância da Educação Financeira para estudantes do ensino básico e tem como objetivo investigar como eles controlam suas finanças, trazendo à tona uma discussão à luz da modernidade líquida de Bauman (2001). Para realizá-lo, foi efetuada uma pesquisa com uma turma do $1^{\circ}$ ano do ensino médio, em uma escola da rede particular, sendo 35 alunos participantes. Foram aplicadas problematizações com o intuito de identificar e analisar seus conhecimentos sobre Educação Financeira. Com base nas respostas das atividades foi possível compreender a relação dos alunos com os recursos financeiros e, para obter uma análise do entendimento dos jovens com relação à Educação Financeira, foi estabelecer algumas estratégias no sentido de orientá-los em suas limitações financeiras. Logo após análise dos dados foi possível constatar uma dificuldade dos alunos no desenvolvimento dos cálculos matemáticos. Concluiu-se que é importante que os alunos sejam educados financeiramente, pois assim, torna-se possível um planejamento em prol da qualidade de vida, em especial, a financeira. Estes resultados foram refletidos e discutidos à luz da concepção de Bauman $(2001,2008)$ a respeito da sociedade "líquida" e, inspirado na Teoria Das Situações Didáticas de Brousseau (1996, 2008), já que envolveram situações em sala de aula, com aluno, com professor e com o saber matemático.
\end{abstract}

Palavras-chave: Educação Matemática. Planejamento familiar. Orçamento. Ética de Consumo.

Abstract: This study discourses on the relevance of Financial Education for Basic Education students, and has the goal of investigating how these students control their finances, bringing to the surface a discussion under the light of Bauman's Liquid Modernity (2001). In orderto do this, a research with 35 students of a $1^{\text {st }}$ year High School class, from a private school, was done. Some situational problems were applied to identify and analyze their knowledge about Financial Education. Based on their answers, it was possible to comprehend their relationship with financial resources, and with the purpose of drawing an analysis of the youngs' understandings about Financial

\footnotetext{
${ }^{1}$ Graduação em Licenciatura em Matemática - Iniciação Científica (Santander) Universidade do Grande Rio, lipe4229@gmail.com

${ }^{2}$ Graduação em Licenciatura em Matemática - Iniciação Científica (Santander) Universidade do Grande Rio, brunopms95@hotmail.com

${ }^{3}$ Estudante do Ensino Médio do Colégio Estadual Dulce Petri - Iniciação Científica Jr. (CNPq),

931john@gmail.com

${ }^{4}$ Profa Dra Chang Kuo Rodrigues (FUNADESP) - PPGEM-UFJF, changkuockr@gmail.com

Tangram - Revista de Educação Matemática, Dourados - MS - v.2 n. 2, pp. 03-15 (2019)
} 


\section{Educação Financeira em Situações de Ensino e de Aprendizagem: Momentos de Reflexão}

Education, it was very convenient to establish some strategies to guide them through their financial limitations. Right after the data analysis, the difficulties of the students during the development of the mathematic calculations became clear. Therefore, we came to the conclusion that is important that the students be financially educated because, that way, the planning aiming at a better life quality, especially financially, becomes possible. These results were discussed under Bauman's conception regarding the so called "liquid society" $(2001,2008)$ and inspired on Brousseau's Theory of didactical situations in Mathematics $(1996,2008)$ since it involved classroom situations with the students, the teacher and the mathematical knowledge.

Keywords: Education Mathematics. Family Planning. Budgeting. Ethics of Consuming.

\section{Introdução}

Este trabalho parte do propósito de expressar a importância de trazer o conhecimento financeiro e promover melhor qualidade de vida entre os alunos da Educação Básica e tem como objetivo investigar como eles controlam suas finanças sob o ponto de vista "líquida" de Bauman (1998, 2001, 2008, 2009, 2017).

Atualmente as escolas carecem de ensino de educação financeira mesmo este sendo essencial para a formação de indivíduo no meio de uma sociedade de consumo. A maioria das iniciativas propostas no Brasil é controlada por instituições financeiras, o que levanta algumas dúvidas sobre as quais interesses essa política realmente quer atender. Educar financeiramente um jovem não é apenas ensinar a lidar com despesas; é uma atividade muito mais ampla, que inclui outros fatores como: ética de consumo, aprender a realidade do crédito, compreender problemas financeiros complexos, organizar conscientemente finanças, utilizar conhecimentos de matemática financeira nas tomadas de decisões, entre outros.

No Brasil, o sistema de produção incentiva o consumo sendo, portanto, de natureza consumista; isso é corroborado quando o hábito da educação financeira não faz parte da realidade da maioria das pessoas, afinal, é um incentivo que o ter seja melhor que o ser, ou seja, as pessoas valem pelo que têm, no sentido de bens materiais.

Vivemos imersos em um labirinto de propagandas que, em seu objetivo predefinido, é usado como forma de incentivar algum tipo de comportamento e nesse sentido, na perspectiva de Bauman (2008), há um incentivo, por parte da mídia, que se aproveita da vulnerabilidade do jovem ao associar consumo com felicidade. Diante disso, o mercado financeiro intitula "estilos de vida ideal" que fazem os jovens buscar desenfreadamente viver esses padrões para se sentirem incluídos em um grupo social. Desta feita, fica a evidência de

Tangram - Revista de Educação Matemática, Dourados - MS - v.2 n. 3, pp. 03 - 15 (2019) 


\section{Educação Financeira em Situações de Ensino e de Aprendizagem: Momentos de Reflexão}

um consumo imediato, em que as pessoas não consomem pela necessidade, mas em busca de uma afirmação em um determinado grupo. O consumo é de fato, hoje, como um efeito de felicidade e bem estar, uma utopia inalcançável, mas vendida.

Em um país desprovido de uma formação na vertente da educação financeira Silva e Powell (2013) reforçam o tema deste trabalho, o qual implica em pensar nas estratégias que as escolas devem adotar sobre educação financeira e quais fatores influenciam na gestão de orçamento pessoal.

Educação Financeira é definida como a habilidade que os indivíduos apresentam ao fazer escolhas adequadas quando administram suas finanças pessoais durante o ciclo de sua vida (Pinheiro, 2008). Assim, a finalidade de educar financeiramente resulta, tal como Cerbasi (2004) defende, em como as pessoas podem reagir, ou até mesmo evitar/prevenir, situações de crise econômica, tal como essa, em termos gerais, que estamos vivenciando nos dias de hoje.

Grande parte da população brasileira e, principalmente, os jovens desconhecem o tema Educação Financeira. Partindo desse princípio, pode-se dizer que as decisões tomadas por essas pessoas afetam seu planejamento orçamentário familiar, tornando-as reféns de situações de desorganização financeira, principalmente no que se refere a relações de consumo e renda. Com base nesse cenário, pode-se constatar que devemos apresentar iniciativas que corroborem para a alfabetização financeira dos estudantes, sobretudo que as mesmas partam do ambiente escolar.

Este trabalho é um convite à reflexão sob a perspectiva do mundo "líquido" (Bauman, 2001) e inspirado na Teoria Das Situações Didáticas de Guy Brousseau, tendo em vista que se trata de práticas em sala de aula, para que cada indivíduo consumidor possa tomar suas decisões corretamente, exercendo a opinião crítica. Desta forma, poderão ocorrer mudanças na realidade de famílias e do meio em que os alunos vivem, com base nas discussões a respeito de ética de consumo, para adquirir habilidades específicas em tomadas de decisões financeiras.

\section{Referencial Teórico}

É da natureza humana valorizar mais o que está sendo visto. É preciso tomar cuidado com a visão distorcida encontrada tão fortemente na realidade de hoje. Uma visão que obscurece tudo que não tem interesse material, mas de fato ignora o que tem maior Tangram - Revista de Educação Matemática, Dourados - MS - v.2 n. 3, pp. 03 - 15 (2019) 


\section{Educação Financeira em Situações de Ensino e de Aprendizagem: Momentos de Reflexão}

significado: a vida e os valores sentimentais. Nesse sentido, Bauman (2001) oferece um caminho frutífero para o entendimento da atual sociedade e do comportamento de seus habitantes, os quais influenciados pelo consumismo podem gerar consequências danosas às suas vidas. Em Modernidade Líquida, Bauman (2001) descreve a necessidade das pessoas se tornarem pensadores críticos para não cumprirem com as obrigações impostas pelo mercado financeiro, seguindo um estilo de vida individualista, que gera insegurança, estresse e ansiedade, e são encarados como "natural" e, por que não, rentáveis para o estilo de vida líquido moderno.

Ao longo de toda a vida é necessário lidar com questões financeiras, pois somos agentes econômicos e nossas decisões sobre esse assunto podem impactar no tempo presente e, também, no futuro. A educação financeira é importante em todas as fases da vida, e aprender desde cedo ajuda a fundamentar nossas atitudes frente ao consumo.

Pode-se constatar que devemos apresentar iniciativas que corroborem para a alfabetização financeira dos estudantes, sobretudo, partindo do ambiente escolar, o que pode evitar a possibilidade de desvio de interesse pedagógico para uma possível "clientelização" do mercado financeiro. Portanto, a presente pesquisa visa atender esta demanda no tocante a sugerir um pensamento crítico aos alunos do ensino básico relacionado às questões econômico-sociais, ao orçamento familiar e às relações de consumo na atualidade. Diante disso, a crítica de Bauman ganha ainda mais importância no que diz respeito aos direitos sociais, isto é, em sua obra intitulada A vida Fragmentada, Bauman (2009, p. 286) descreve sobre o resgate da cidadania, quando "[...] os programas de assistência governamental convidam o cidadão excluído a retornar à sociedade, valorizando-o e abrindo portas, resolvendo a dificuldade estrutural da desigualdade social".

\section{Procedimentos Metodológicos}

A abordagem da pesquisa é de natureza qualitativa, pois tem a intenção de conhecer a relação entre os saberes dos sujeitos da pesquisa e os conceitos de educação financeira. De fato, nas palavras de Godoy (1995, p.58), “[...] é a obtenção de dados descritivos sobre pessoas, lugares e processos interativos pelo contato direto do pesquisador com a situação estudada, para compreender os fenômenos segundo a perspectiva dos sujeitos, ou seja, dos participantes da situação em estudo". Além disso, vale destacar que os métodos de pesquisa qualitativa estão voltados para auxiliar os pesquisadores a compreenderem pessoas e seus Tangram - Revista de Educação Matemática, Dourados - MS - v.2 n. 3, pp. 03 - 15 (2019) 


\section{Educação Financeira em Situações de Ensino e de Aprendizagem: Momentos de Reflexão}

contextos sociais, culturais e institucionais, podendo assim, intervir na realidade em que estão.

A escolha metodológica seguiu a proposta de Brousseau (1996), Teoria das Situações Didáticas, pelo fato de interpretar as relações entre alunos-professor no ambiente onde acontece o aprendizado e os alunos ganham a posição de destaque no local de ensino em situações reflexivas e argumentativas. "O aluno aprende adaptando-se a um meio que é um fator de contradições, de dificuldades, de desequilíbrios, um pouco como faz a sociedade humana. Este saber, fruto da adaptação do aluno, manifesta-se através de respostas novas, que são a prova da aprendizagem.” (Brousseau, 1996, p.49).

A Teoria das Situações Didáticas, segundo Brousseau (2008), emerge do conceito de que cada conhecimento ou saber pode ser determinado por uma situação de ensinoaprendizagem, Figura 1, entendida como uma ação entre duas ou mais pessoas. Nesse sentido, levará o aluno a pensar, agir, refletir sobre a ação e validar os argumentos usados para sustentar suas respostas.

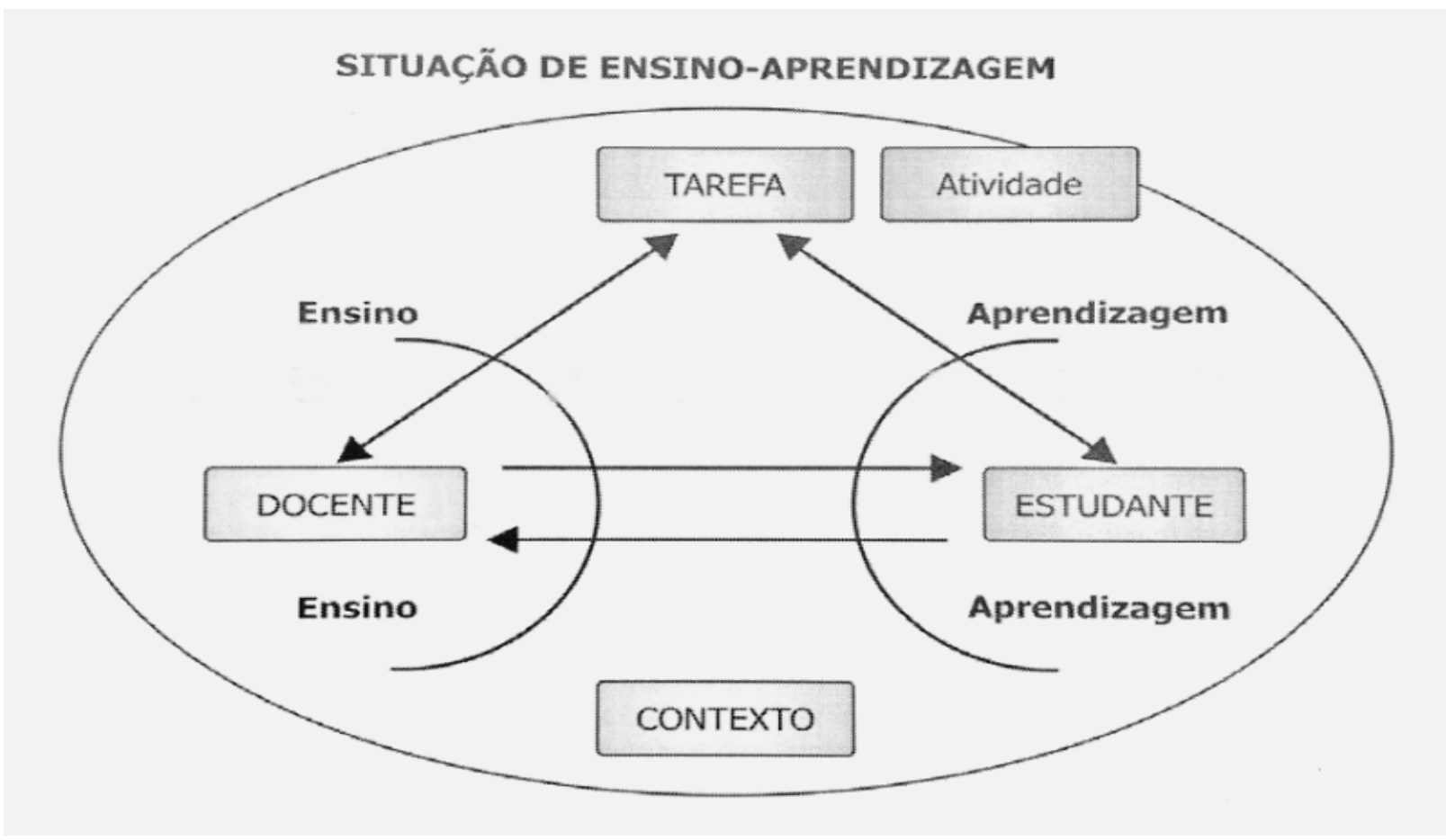

Figura 1 - Triângulo da aprendizagem

Fonte: Brousseau, 2008, p.19

Tangram - Revista de Educação Matemática, Dourados - MS - v.2 n. 3, pp. 03 - 15 (2019) 


\section{Educação Financeira em Situações de Ensino e de Aprendizagem: Momentos de Reflexão}

Segundo Silva (2008), inspirada nas ideias de Brousseau, o aluno somente constrói o conhecimento quando se envolve pessoalmente com o problema proposto pela situação. A situação didática é planejada com a intenção de o aluno construir seu saber, sendo estas situações de diferentes tipos, isto é, situações de ação, de formulação, de validação, e de institucionalização.

Diante disso, vale destacar que a teoria de Brousseau permite que o ensino da matemática seja mais prático, já que os educandos devem se tornar ativos e habilitados a criar e validar suas ideias dentro do ambiente de ensino e aprendizagem.

\section{Problematização Desenvolvida}

O trabalho de campo consistiu na resolução de um conjunto de atividades de investigação, as quais foram implementadas em sala de aula, em três encontros. As atividades foram dividias em três tarefas, seguindo as propostas de Silva (2017).

Houve uma busca pela contextualização das tarefas com o cotidiano do aluno. Aprofundando-se nas ideias de Skovsmose (2007), que diz que a investigação gera habilidade crítica para desenvolver a capacidade de interpretar e analisar sinais e linguagens, de propor e utilizar situações problemas com a vida cotidiana dos alunos, de elaborar situações com representação da realidade, conjecturar as habilidades matemáticas e conceber momentos de autorreflexão alicerçados pela Educação Matemática. Ainda sobre isso, Skovsmose (2007) aprofunda a ideia quando diz que:

Um cenário para investigação é aquele que convida os alunos a formular questões e a procurar explicações. O convite é simbolizado por seus "Sim, o que acontece se...?". Dessa forma os alunos se envolvem no processo de exploração e explicação. O "Por que isto? "Do professor representa um desafio, e os "Sim, por que isto...? Dos alunos indicam que eles estão encarando o desafio e estão em busca de explicações, o cenário de investigação passa a constituir um novo ambiente de aprendizagem. No cenário de investigação os alunos são responsáveis pelo processo. (Skovsmose, 2007, p. 21).

As tarefas foram desenvolvidas obedecendo ao Plano Pedagógico da Escola, que é norteado pelos Parâmetros Curriculares Nacionais (PCN), os quais orientam as escolas a desenvolver os conceitos de Juros e Taxas no quarto ciclo do Ensino Fundamental, ( $9^{\circ}$ ano). Vejamos, a seguir, as atividades.

Tangram - Revista de Educação Matemática, Dourados - MS - v.2 n. 3, pp. 03 - 15 (2019) 


\section{Educação Financeira em Situações de Ensino e de Aprendizagem: Momentos de Reflexão}

Esta atividade, a primeira, Figura 2, foi separada em duas tarefas, na primeira foi abordada a temática "Desconto Falso" e na segunda tarefa "Black Friday". Os alunos reuniram-se em grupos de três que, segundo Hill e Hill (2012), nos trabalhos de campo envolvendo problematizações, são o número ideal para se formar os grupos. Desta forma os alunos puderam conversar entre eles, porém as respostas foram individuais:

1- Ao passar em frente a uma lanchonete, Gabriel vê o seguinte anúncio: "Compre um hambúrguer e ganhe $50 \%$ de desconto no segundo hambúrguer". Gabriel fica super empolgado e compra os dois hambúrgueres, já que estava levando pela metade do preço.

a) Para Gabriel, ele comprou os dois hambúrgueres pagando $50 \%$ de desconto no total da compra. Você concorda com ele? Por quê?

b) Se você respondeu no item anterior que o desconto obtido por Gabriel ao final da compra não foi de $50 \%$, informe qual foi a verdadeira porcentagem do desconto.

2- Você já ouviu falar sobre a Black Friday? Acredito que já. A Black Friday é uma tradição estadunidense, mas que se espalhou por todo o mundo. Nos Estados Unidos, acontece na última sexta-feira do mês de novembro. Neste dia o comércio anuncia promoções e liquidações para atrair o público, propiciando uma intensificação de suas vendas. Ela foi criada com a finalidade dos consumidores comprarem seus presentes de Natal antecipadamente. Podemos conversar um pouco sobre a Black Friday no Brasil, já que em algum momento tivemos acesso a informações sobre esse acontecimento através dos enfeites e cartazes nas lojas, panfletos nas ruas e propagandas em TV e internet.

Você e sua família têm o hábito de aguardar o dia da Black Friday para fazer compras? Já compraram algum produto na Black Friday?

Figura 2 - Atividade 1

Fonte: Silva, 2017 (Adaptada)

Para Atividade 2, Figura 3, esta tarefa trouxe a temática "Compra à vista ou a prazo", já que muitas pessoas questionam sobre qual forma de pagamento utilizar. Além disso, serviu para identificar a habilidade de tomadas de decisões dos alunos e puderam-se avaliar cada situação e ver o que eles apresentaram do que seria mais vantajoso:

Tangram - Revista de Educação Matemática, Dourados - MS - v.2 n. 3, pp. 03 - 15 (2019) 


\title{
Educação Financeira em Situações de Ensino e de Aprendizagem: Momentos de Reflexão
}

\begin{abstract}
Gustavo e Mariana gostaram de um mesmo modelo de moto, no valor de $\mathrm{R} \$ 12.000,00$. Ambos tinham esse valor em dinheiro para a aquisição da moto. Gustavo comprou a moto na Loja $\mathrm{A}$, na qual foi oferecido, pelo vendedor, duas opções de pagamento: $10 \%$ de desconto para pagamento à vista ou 12 vezes de $\mathrm{R} \$ 1.000,00$ (sem juros). Já Mariana acabou comprando na Loja B, na qual o vendedor ofereceu também duas opções de pagamento: $5 \%$ de desconto para pagamento à vista ou 24 vezes de $\mathrm{R} \$ 500,00$ (sem juros).

Agora responda:

a). Fazendo as contas, Gustavo deveria comprar à vista ou a prazo? Por que essa seria a melhor escolha?

b). Na opção parcelada, Gustavo colocasse o valor da moto à vista rendendo numa poupança com uma taxa de $0,5 \%$ e $0,7 \%$ ao mês. $O$ que você diria sobre a melhor opção de pagamento, à vista ou a prazo? Por quê?
\end{abstract}

Figura 3 - Atividade 2

Fonte: Silva, 2017 (Adaptada)

A Atividade 3, Figura 4, foi dividida em duas tarefas: A primeira relacionando Educação Financeira e Meio Ambiente e, a segunda, desenvolvida com base no que cada aluno pôde identificar sobre o que seria essencial, necessário ou supérfluo.

1 - Na hora de comprar algum produto e/ou alimento você leva em consideração a sustentabilidade do planeta? Se você respondeu no item anterior que sim, cite quais.

2 - Cite três coisas que você considera que são "essenciais" em sua vida; cite três coisas que você considera que são "necessárias" em sua vida; cite três coisas que você considera "supérfluo" em sua vida.

Figura 4 - Atividade 2

Fonte: Dados da pesquisa

Diante dessas atividades, Figuras 2, 3 e 4, nos foi permitir refletir e discutir os resultados apurados a respeito de como os alunos envolvidos na pesquisa pensam sobre situações do dia a dia que envolvem práticas financeiras.

Tangram - Revista de Educação Matemática, Dourados - MS - v.2 n. 3, pp. 03 - 15 (2019) 


\section{Educação Financeira em Situações de Ensino e de Aprendizagem: Momentos de Reflexão}

\section{Discussão dos Resultados}

As atividades elaboradas durante o período da pesquisa tiveram a duração de 50 minutos, entretanto, após as tarefas do terceiro encontro, ocorreu um debate mais intensivo sobre a temática das tarefas. Dessa forma, esse encontro durou 140 minutos. Nesta fase da pesquisa, foi realizada uma análise das respostas das atividades, e algumas respostas das tarefas de cada aula foram selecionadas para representar o trabalho. Por meio dessas problematizações, foi possível identificar a forma com que os alunos defrontaram-se com suas finanças e pôde-se perceber uma dificuldade dos alunos em relação aos saberes matemáticos, no que diz respeito à matemática financeira. Além disso, apenas seis dos trinta e cinco alunos conseguiram responder corretamente as tarefas envolvendo porcentagem de desconto.

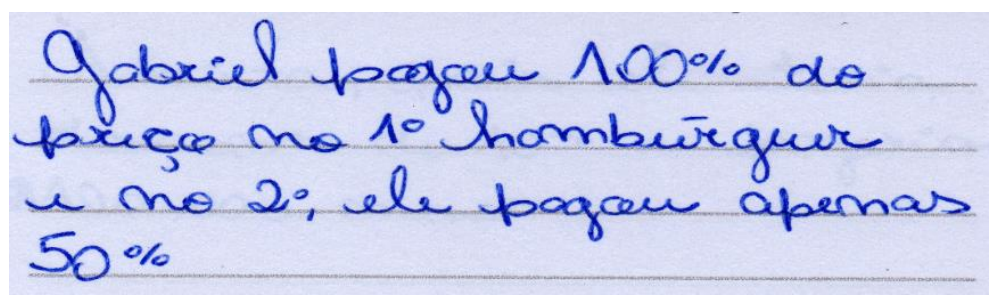

Figura 5 - Resposta de um aluno para atividade 1.a Fonte: Dados da pesquisa

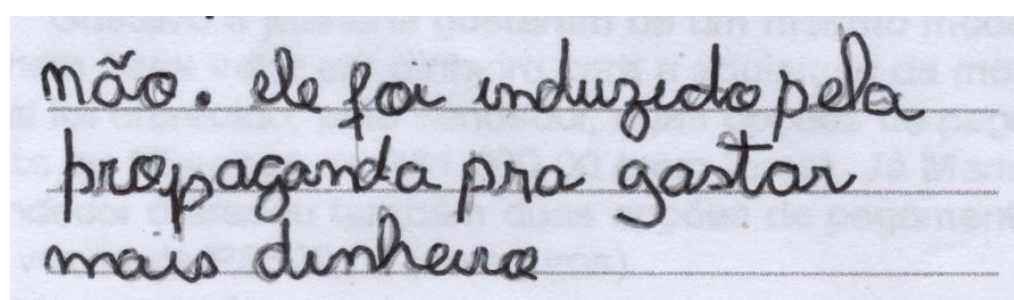

Figura 6 - Resposta de um aluno para atividade 1.b Fonte: Dados da pesquisa

As figuras 5 e 6 representam a maioria das repostas já que, nesse caso, os alunos compreenderam a tentativa de persuasão da lanchonete, porém, apenas seis alunos souberam informar qual foi a verdadeira porcentagem do desconto no total da compra.

Diante disso, o presente trabalho se relaciona com a teoria de Brousseau (2008) ao revelar e construir condições que possam indicar situações de aprendizagem de um indivíduo por meio de saberes matemáticos, de modo que o aluno, experimentando situações de uma 


\section{Educação Financeira em Situações de Ensino e de Aprendizagem: Momentos de Reflexão}

realidade, traga pela mesma um conhecimento, e ao utilizar esse conhecimento, consiga construir seu próprio saber.

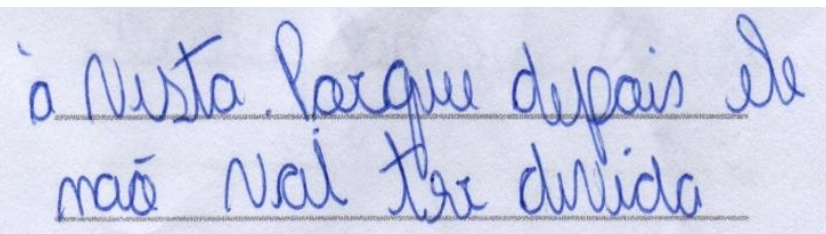

Figura 7 - Resposta de um aluno Fonte: Dados da pesquisa

A resposta de um aluno da Figura 7 é pessoal, pois envolve outros fatores além do desconto. Muitas pessoas acreditam que o pagamento à vista, quando se tem desconto, é sempre mais vantajoso, para outros, o pagamento à vista pode ser vantajoso por não gostar de parcelar, já que estariam contraindo uma dívida. Assim como para outras pessoas o parcelamento é o que cabe em seu orçamento, entre outros motivos.

Dessa forma, o desenvolvimento de situações como esta implica na Teoria das Situações Didáticas de Brousseau, que possibilita desenvolver habilidades e estratégias a serem utilizadas futuramente pelos alunos.

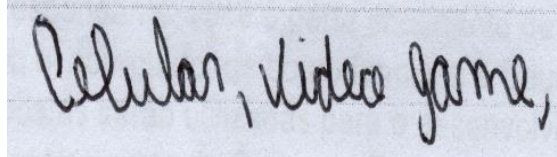

Figura 8 - Resposta de um aluno Fonte: Dados da pesquisa

A Figura 8 representa a maioria das respostas dos alunos de gênero masculino. Diante desse cenário, a crítica de Bauman (2008) ganha ainda mais destaque, que o ter tornou-se mais importante que ser, visto que as respostas dos alunos dentre as "coisas que são essenciais" os aparelhos eletrônicos foram os mais citados como essenciais para as suas vidas. Entre esses, o vídeo game é o que mais aparece, no todo são oito respostas citando o aparelho. 


\section{Educação Financeira em Situações de Ensino e de Aprendizagem: Momentos de Reflexão}

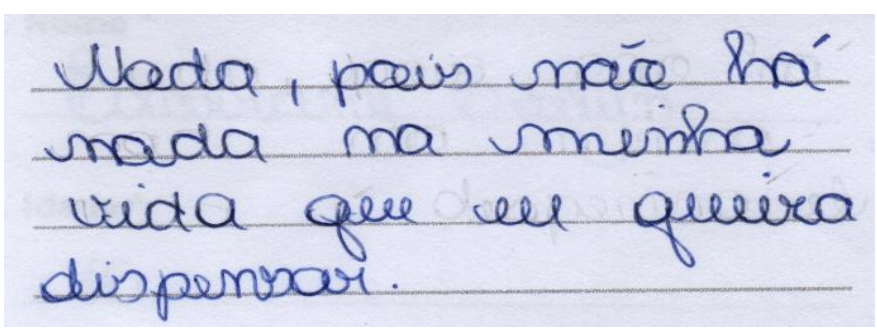

Figura 9 - Resposta de um aluno

Fonte: Dados da pesquisa

A Figura 9 foi usada como um dos temas na discussão após o término da tarefa. Como as respostas são anônimas, por isso dentre elas, a análise foi pela resposta em si e não a partir da identificação desse ou do outro, já que esta resposta, Figura 9, evidencia como ainda há apego a objetos e produtos.

Ao analisar todas as respostas fica explícito que os alunos estão sendo facilmente "ludibriados", ou melhor, iludidos pelo mercado financeiro, influenciados pelo consumismo desenfreado. Desta forma, valida a hipótese desta pesquisa, que o ensino de Educação Financeira na Educação Básica despertará nos indivíduos habilidades para identificar e desenvolver ações que ajudem na tomada de decisão e a se conscientizarem financeiramente.

\section{Considerações Finais}

Este trabalho teve como objetivo investigar e identificar como os alunos do ensino básico veem a Educação Financeira, como lidam com suas finanças e como as famílias e a escola auxiliam na formação desses jovens. A coleta de dados teve um campo de atuação restrito, mas é necessário que se façam novas amostragens com um número maior de alunos, de distintas regiões para que as informações obtidas obtenham maior exatidão, no sentido quantitativo.

Potenciado pelos tempos de crise que o país atravessa, fala-se mais em Educação Financeira e na necessidade de ensinar esta temática desde o ensino básico. Esta vertente da informação deve proporcionar aos cidadãos dados de conhecimento especifico para tornálos conscientes das oportunidades financeiras e para desenvolverem habilidades de tomadas de decisões financeiras e suas consequências.

Espera-se que os alunos adquiram habilidades para identificar e desenvolver ações que os ajudem a ser financeiramente mais conscientes e para que se protejam do consumismo desenfreado, que está em constante tensão com nossos valores e com nosso orçamento.

Tangram - Revista de Educação Matemática, Dourados - MS - v.2 n. 3, pp. 03 - 15 (2019) 


\section{Educação Financeira em Situações de Ensino e de Aprendizagem: Momentos de}

Reflexão

\section{Agradecimentos}

CNPQ - Conselho Nacional de Desenvolvimento Científico e Tecnológico

\section{SANTANDER}

FUNADESP - Fundação Nacional de Desenvolvimento do Ensino Superior

\section{Referências}

Bauman, Zygmunt. (1998). O mal-estar da pós-modernidade. Rio de Janeiro: Jorge Zahar. . (2001). Modernidade Líquida. Trad. Plinio Dentzien. Rio de Janeiro: Zahar. (2008). Vida para consumo: a transformação das pessoas em mercadorias. Trad. Carlos Alberto Medeiros. Rio de Janeiro: Jorge Zahar.

. (2009). A arte da Vida. Trad. Carlos Alberto Medeiros. Rio de Janeiro: Jorge Zahar. (2017). A Vida Fragmentada:Ensaios sobre a Moral Pós-Moderna. Trad. Miguel Serras Pereira. Rio de Janeiro: Relógio D'Água.

Brasil. (1998). Secretaria de Educação Fundamental. Parâmetros Curriculares Nacionais para Ensino Fundamental (PCNEF): Matemática. Brasília: SEMT/MEC.

Brousseau, G. (1996). Introdução ao estudo das situações didáticas: conteúdos e métodos de ensino. Trad. Camila Bogéa. São Paulo: Ática.

. (2008).Introdução ao estudo das situações didáticas: conteúdos e métodos de ensino. São Paulo: Ática.

Godoy, A. S. (1995). A Pesquisa Qualitativa e Sua Abordagem.Revista de Administração de Empresas / EAESP / FGV, São Paulo, Brasil.

Hill, M.M; Hill, A. (2012). Investigação por questionário. Lisboa: Edições Súlabo.

Machado, S. D. A. (2002). Engenharia Didática. In: Machado, S. D. A. (Org.).Educação Matemática: Uma introdução. 2 ed. São Paulo: Educ. p. 197-208.

Pinheiro, M. O. (2008). As Relações Didático-Pedagógicas no Ensino de Geometria com o Software CabreGeometre. Curitiba.

Silva, Amarildo Melchiades da; Powell, Arthur Belford. (2014). Educação Financeira na Escola: a perspectiva da Organização para Cooperação e Desenvolvimento Econômico, Boletim Gepem (ISSN: 2176-2988), 66.

Silva, V. H. B. C. (2017). Educação Financeira Escolar: os riscos e as armadilhas presentes no comércio, na sociedade de consumidores. Universidade Federal De Juiz De Fora -

Tangram - Revista de Educação Matemática, Dourados - MS - v.2 n. 3, pp. 03 - 15 (2019) 
Educação Financeira em Situações de Ensino e de Aprendizagem: Momentos de Reflexão

Instituto De Ciências Exatas Programa De Pós-Graduação Em Educação Matemática Mestrado Profissional Em Educação Matemática, Juiz de Fora, MG, Brasil.

Skovsmose, O. H. (2007). Diálogo e Aprendizagem em Educação Matemática. Trad. Orlando Figueiredo. Belo Horizonte: Autêntica.

Enviado:01/10/2018

Aceito:06/03/2019

Tangram - Revista de Educação Matemática, Dourados - MS - v.2 n. 3, pp. 03 - 15 (2019) 